\title{
Ethical, green and sustainable nuclear medicine
}

\author{
Alan C. Perkins \\ Published online: 30 April 2013 \\ (C) Springer-Verlag Berlin Heidelberg 2013
}

\section{Introduction}

We in the nuclear medicine community have always taken pride in the fact that our use of radioactive materials in the form of radiopharmaceuticals is without question for the good of both our patients and mankind in general. Whilst the "nuclear debate" has focused on the use of nuclear power, nuclear medicine has distanced itself from such discussions, mainly on the basis that nuclear reactors producing electric power are not used for the production of medical radioisotopes. After all, nuclear medicine was born out of the use of "atoms for peace" in the aftermath of the Second World War and this also led to the formation of the International Atomic Energy Agency [1].

It is interesting that with attempts to reduce carbon emissions to the atmosphere, nuclear power generation is now being adopted by a number of governments as a "green" solution to meet national energy demands. This is resulting in a revival of interest in nuclear reactor technologies that may have some interesting future spin-off applications.

\section{Source and supply}

The more recent concerns regarding the ongoing security of medical radioisotope supplies has raised a number of issues relating to the source, manufacture, waste products and transportation of medical radionuclides. In addition it has to be appreciated that economic, environmental and social factors are important for the ongoing provision of nuclear medicine services.

Given that nuclear medicine services are still largely based on the use of ${ }^{99 \mathrm{~m}} \mathrm{Tc}$ radiopharmaceuticals, it is necessary to

\footnotetext{
A. C. Perkins $(\bowtie)$

Radiological and Imaging Sciences, The School of Medicine, University of Nottingham, Nottingham, UK

e-mail: alan.perkins@nottingham.ac.uk
}

consider the origin and manufacture of the source materials required for ongoing radionuclide production. Such considerations have international political, economic and social dimensions. The starting material for reactor fuel and source targets is ${ }^{235} \mathrm{U}$. Uranium is mined in various locations around the world with Kazakhstan, Canada and Australia accounting for over $60 \%$ of world production. Other producers include Namibia, Russia, Niger, Uzbekistan and the USA. The operation of uranium mines has had a questionable history. It goes without saying that mine workers are potentially at risk of relatively high occupational exposure to radiation, notably radon, but they are also exposed to high levels of arsenic and dust that have led to high incidences of lung cancer in this population. In the past the mining industry relied on itinerant workers who did not stay in the job long enough to accumulate high annual radiation doses. Risks of accidents, tuberculosis, noninfectious respiratory diseases, cirrhosis and homicide deaths are also related to the life-style associated with mining [2,3]. Increasing awareness and health and safety legislation has improved uranium mining operations in many countries, and there is a far better understanding of the environmental impact of mining waste products and mill tailings in water courses and ground spoils, leading to improved bioremediation in mining areas [4].

\section{Security}

The recent measures taken to ensure the future security of supplies have focused on the irradiation of source targets by reactor operators and the manufacture and distribution of ${ }^{99} \mathrm{Mo} /{ }^{99 \mathrm{~m}} \mathrm{Tc}$ generators. The Nuclear Energy Agency of the Organisation for Economic Co-operation and Development (OECD) has played an important role in bringing together producers, manufacturers, government officials and users with the aim of securing future supplies. This has produced a number of useful outcomes including a better understanding of the international market economy, the need for full 
economic costing, ensuring reserve production capacity and the coordination of reactor schedules. In this sense, security has a double meaning, since security of supply also involves reduction of the global nuclear threat $[5,6]$. It should be appreciated that radionuclides such as ${ }^{99}$ Mo have traditionally been produced from nuclear reactors in which both the fuel and the source targets comprise weapons grade highly enriched uranium (HEU). Operational licence violations at the National Research Universal reactor in Canada in 2007 led the Canadian government to question why the world was dependent upon Canada for some $40 \%$ of ${ }^{99 \mathrm{~m}}$ Mo production. Canada was importing about $20 \mathrm{~kg}$ of HEU from the USA annually to produce medical radionuclides. In the process of manufacture, about $97 \%$ of the weapons grade material remained unused. In the same year armed attackers gained access to the control room of the Pelindaba reactor site in South Africa $[6,7]$. Apparently the attacker's aims were to steal valuable computer equipment, but the authorities were well aware that the site contained considerable amounts of HEU that could have been used for illicit purposes including nuclear terrorism.

In the post-9/11 era, it has been recognized that there is a compelling need for change. The USA in particular has led the move from reactor operation using HEU to low enriched, non-weapons grade uranium (LEU). This also applies to the use of the uranium targets used for the production of ${ }^{99} \mathrm{Mo}$. All major long-term global suppliers of ${ }^{99}$ Mo have committed to conversion to production from LEU sources. A number of producers such as IRE in Belgium and Mallinckrodt-Covidien have firm plans in place to convert. Some of the newer entrants to the global ${ }^{99} \mathrm{Mo}$ market have no plans for conversion. Inevitably conversion of target irradiation and extraction processes from HEU to LEU will result in a more expensive product. This will lead to an increased cost to consumers with no immediate perceived benefit. To exacerbate the issue, shortages of supplies, introduction of full cost recovery and the provision of any reserve production capacity all add to the consumer cost. This can make nuclear medicine procedures appear more expensive in comparison to other diagnostic imaging modalities. However, establishing service reliability is paramount, and without these measures in place the long-term provision of supplies is in question and future services may be at risk. The OECD High-level Group on the Security of Supply of Medical Radioisotopes (HLG-MR) has been instrumental in creating policy in support of long-term provision $[8,9]$. The policy approach includes:

- Making the purchase of non-HEU-based ${ }^{99}$ Mo more attractive

- Making the purchase of HEU-based ${ }^{99}$ Mo less attractive

- Limiting access to HEU-based ${ }^{99} \mathrm{Mo}$ (via import/export controls)
In the USA the White House Group has embraced and promoted the use of non-HEU materials in medicine. The American Medical Isotope Production Act enacted this year directs the US Department of Environment to pursue the domestic production and use of radiopharmaceuticals using non-HEU materials and to phase out the export of HEU materials for medical isotope production [10]. It will be interesting to observe what effect this has on the supply and purchase of ${ }^{99} \mathrm{Mo} /{ }^{99 \mathrm{~m}} \mathrm{Tc}$ generators in the USA and further afield.

In future the routine production of ${ }^{99 \mathrm{~m}} \mathrm{Tc}$ (or suitable alternative radiolabels) may be possible by the irradiation of targets in medical accelerators or cyclotrons [11]. This would reduce some of the above risks, however much work is required to ensure product purity, efficiency and safety as well as to demonstrate a sound business model for regional supplies. This may solve some of the issues surrounding the operation of nuclear reactors, but even with this approach, the political, social and environmental issues remain.

\section{Ethical purchasing}

The production of ${ }^{99} \mathrm{Mo}$ for the hospital radiopharmacy involves the irradiation of the ${ }^{235} \mathrm{U}$ targets by the reactor operators. Only a small fraction of the market cost reaches the reactor operators and each step in the manufacturing chain adds value and hence cost to the final medical product. The implementation of the policy of "full cost recovery" promoted by the HLG-MR at the OECD is intended to provide a commercial model to support the investment required by producers for the long-term operation of production facilities. It is evident, however, that some producers are not taking full costs into account (by only accounting for short-term production, or through subsidies granted by national governments) and are supplying ${ }^{99} \mathrm{Mo}$ to the market at unrealistic prices. This practice is unsustainable and is not in the long-term interest of nuclear medicine as a specialty.

There is now a need to educate practitioners and healthcare providers on the responsibilities of purchasing medical radioactive materials, taking regard of the ethical, environmental and social impact of production and use. In many countries the "Fair Trade" movement has arisen from customer desires to make ethical and morally sound purchases. This has influenced the placement and marketing of a wide range of consumer products. Medical practitioners have a strong and traditional regard for high ethical standards. This should extend to the ethical purchasing of radiopharmaceuticals, where consideration of LEU production, low waste/low environmental impact and sustainability is taken into account. The Lantheus/Mallinckrodt "green dot" LEU generator is a first move in recognition of this, with the green label 
indicating production by LEU production methodologies. It would be desirable to see this approach to product labelling extended, encouraging radiopharmacy units to take account of wider issues than just the cheapest supplier of generators.

In future those making the purchase of ${ }^{99} \mathrm{Mo}$ generators will have a choice between HEU and LEU production. The power to change practices is in the hands of those individuals who make decisions on the purchase and use of the radiopharmaceuticals that are needed to best serve our patients and society in general.

\section{Conflicts of interest None.}

\section{References}

1. Krige J. Atoms for peace, scientific internationalism, and scientific intelligence. Osiris. 2006;21:161-81.
2. Tomásek L, Swerdlow AJ, Darby SC, Placek V, Kunz E. Mortality in uranium miners in west Bohemia: a long-term cohort study. Occup Environ Med. 1995;51:308-15.

3. Brugge D, Goble R. The history of uranium mining and the Navajo People. Am J Public Health. 2002;92:1410-9.

4. Landa ER, Gray JR. US Geological survey research on the environmental fate of uranium mining and milling wastes. Environ Geol. 1995;26:19-31.

5. Covington N. Medical isotope production and nuclear terrorism. CMAJ. 2008;179:54-5.

6. Hansell C. Nuclear medicine's double hazard. Imperiled treatment and the risk of terrorism. Nonproliferation Rev. 2008;15:185-208.

7. Wines M. Break-in at nuclear site baffles South Africa. New York Times, 15 November 2007, p. A3.

8. Nuclear Energy Agency. The supply of medical isotopes: the path to reliability. NEA 6985. Issy-les-Moulineaux: Nuclear Energy Agency, OECD; 2011.

9. Nuclear Energy Agency. The supply of medical isotopes: market impacts of converting to Low-enriched uranium targets for medical isotope production. NEA 7129. Issy-les-Moulineaux: Nuclear Energy Agency, OECD; 2012.

10. Congress passes American Medical Isotope Production Act. J Nucl Med. 2013;54:11N.

11. Pillai MR, Dash A, Knapp FF. Sustained availability of $99 \mathrm{mTc}$ : possible paths forward. J Nucl Med. 2013;54:313-23. 